\title{
Propuesta
}

\section{Proyecto de Ley Orgánica de Ordenamiento Territorial y Político}

\begin{abstract}
Alberto Mendoza Morales*
Artículo 1. Objeto de la ley. La presente ley tiene por objeto establecer los principios rectores del ordenamiento territorial y político de Colombia y dictar las normas que regirán dicho ordenamiento.

Artículo 2. Ámbito y fin de la ley. El ámbito de la ley orgánica es el territorio del Estado definido en el artículo 101 de la Constitución Nacional, su fin es armonizar población, territorio y gobierno, su objeto garantizar la sustentabilidad del medio, la calidad del ambiente, el

Artículo 3. Definiciones. Ordenamiento territorial es la distribución espacial sobre el territorio del país, de las regiones geográficas, las comunidades humanas, las divisiones político-administrativas y los usos del suelo, urbanos y rurales, existentes y propuestos. El Ordenamiento Político es se refiere a la definición de unidades político-administrativas, su funcionamiento, distribución de competencias, formas de crearlas y suprimirlas y maneras de dirimir conflictos de competencias.
\end{abstract} bienestar de la población y su propósito, alcanzar la óptima administración pública.

$\overline{\text { * Arquitecto, }}$ Presidente Sociedad Geográfica de Colombia. 
EL orden territorial comprende los aspectos geográfico, urbano, rural y los que resulten de los usos de la tierra y su regulación. ambiental, étnico-cultural, político-administrativo.

Artículo 4. Leyes reglamentarias. $\mathrm{La}$ presente ley orgánica se desagregará en leyes reglamentarias correspondientes cada una a los órdenes y variables que el ordenamiento territorial necesite: ley geográfica, ley ambiental, ley de asentamientos humanos, ley de entidades político-administrativas, ley de fronteras, ley de los mares, ley ruralística y agraria, ley urbanística, ley de turismo, ley minera y las que sean necesarias para el cabal cumplimiento del propósito.

Artículo 5. Principios del ordenamiento territorial. Principios rectores del ordenamiento territorial serán los siguientes:

1. Diversidad, heterogeneidad $y$ variedad. La diversidad geográfica del país, la heterogeneidad étnico-cultural de los grupos humanos que lo habitan y la variedad de las entidades políticoadministrativas que lo componen, son los elementos fundamentales del ordenamiento territorial y político de Colombia.

2. Integralidad. El ordenamiento se tratará como materia integral, física y ambienal, social y económica, política y administrativa.

3. Sustentabilidad. El ordenamiento territorial conciliará el gobierno, el uso de la tierra, las características geoam-bientales del territorio y de las poblaciones, a fin de garantizar la salud del medio, la sustentabilidad de los recursos y la calidad de vida de la población.

Artículo 6. Instrumentos del ordenamiento territorial. Son Instrumentos del ordenamiento territorial, el Plan Nacional de Ordenamiento Territorial y el Sistema Institucional para su cumplimiento.

\section{Plan Nacional de Ordenamiento Territorial. El Plan Nacional de Ordenamiento Territorial estará compuesto por el conjunto de planes de ordenamiento formulados en municipios, departamentos, regiones, áreas metro- politanas, espacios continentales y demás componentes del territorio nacional. Serán contenidos principales del plan de ordenamiento territorial:}

a. Usos del suelo: 1. Cobertura del suelo; 2. Zonificación general de usos existentes; 3. Estudio de compatibilidad e incompatibilidad de los usos existentes; 4. Usos propuestos; 5. Destinación exclusiva de suelos para cuidado y conservación de áreas de tratamiento especial, áreas sagradas, parques nacionales, áreas de interés histórico o cultural, áreas de reserva, áreas de uso restringido.

b. Mapa de riesgos y clasificación de territorios según grados de fragilidad o peligrosidad por eventos naturales, base para establecer su tratamiento y la intervención correctiva, oportuna y eficaz del Estado. 
c. Zonas de frontera: 1. criterios de integración; 2. obras binacionales; 3 . Ejes binarios urbanos internacionales.

e. Distribución territorial de obras de infraestructura y red vial nacional.

2. Sistema Institucional. El ordenamiento territorial funcionará bajo una Dirección Nacional de Ordenamiento Territorial, el Órgano Técnico, la Secretaría y los Comités de Apoyo. El sistema dependerá de la vicepresidencia de la república, gozará de autonomía de manejo; su funcionamiento atenderá el principio de la descentralización y la autonomía de las entidades políticoadministrativas y contará con recursos que le asignará el gobierno nacional.

Artículo7. Entidades Territoriales. El ordenamiento territorial del país comprenderá entidades territoriales geográficas y unidades políticoadministrativas.

Artículo 8. Entidades territoriales geográficas. Entidades territoriales geográficas son aquellas configuraciones terrestres naturales que contienen alguna característica físico-ambiental que las identifica y define, selva, mar, río, llanura, lago, montaña, etc.

Las entidades geográficas tienen ser propio, existen por sí mismas, las aporta la naturaleza, se delimitan según linderos arcifinios, no se decretan, se reconocen $y$ se dibujan en mapas, las ordena y modifica la naturaleza misma, el hombre las habita, las utiliza, las modifica, las equipa y las tiene como escenario de su relación con la tierra y su devenir histórico.

Artículo 9. Clases de entidades territoriales geográficas. Son entidades territoriales geográficas los espacios continentales, las regiones, las cuencas hidrográficas y otras que, en conjunto, conforman el territorio del país.

Las entidades territoriales físicas serán demarcadas por el Instituto Geográfico Agustín Codazzi (IGAC) con intervención del Ministerio del Medio Ambiente, el Instituto de Hidrografía, Meteorología y Medio Ambiente (IDEAM), el Instituto de Geología y Minas (INGEOMINAS), el Departamento Administrativo Nacional de Estadística (DANE) y la Sociedad Geográfica de Colombia.

Espacios continentales son macro regiones físicas distintas entre sí, de identidad específica, de diferentes dimensiones, que suelen pertenecer a uno, dos o más países y aportan base geopolítica para sus relaciones, tratados y manejo fronterizo. Los espacios continentales de Colombia son seis: Amazonia, Orinoquia, Espacio Marabino, Espacio Andino, Espacio Caribe y Espacio Pacífico.

Los espacios continentales podrán contener una o varias unidades políticoadministrativas, según sus características históricas, culturales y económicas y conforman la primera división administrativa del país. 
Los espacios continentales constituyen, en su calidad de regiones geográficas, entidades de planificación del país; constituirán entidades organizadas para la planificación y la administración; su variedad se expresará en Planes de Ordenamiento Territorial diferenciales, de acuerdo con sus especiales y propias características.

El Plan de Ordenamiento de cada espacio continental será formulado de manera mancomunada, mediante la concurrencia deliberada de las entidades políticoadministrativas que tienen asiento en el respectivo espacio. La integración armónica de los seis planes macro regionales constituirá el Plan Nacional de Ordenamiento Territorial.

2. Regiones. Son regiones aquellos territorios discernibles que componen los espacios continentales; se caracterizan por sus condiciones físico-ambientales individuales que las diferencias entre sí. Las regiones serán graficadas en mapas correspondientes a cada espacio continental.

Los planes de las regiones se formularán en concordancia con el de los espacios continentales que las contienen.

3. Cuencas hidrográficas. Son cuencas hidrográficas aquellas concavidades terrestres por donde corren un río principal y sus afluentes. Además de fluviales, las cuencas hidrográficas son también oceánicas y lagunares, según las comanden un océano o un lago. Las cuencas hidrográficas, sustentadoras del agua, serán objeto de ordenamiento territorial específico y tratamiento especial según su condición y tamaño.

\section{Artículo 10. Ordenamiento territorial} ambiental. Ambiente es el conjunto de circunstancias, condiciones, cosas e influencias, vivientes o inanimadas, que se dan en un determinado territorio. El ordenamiento territorial ambiental del país que se expresa en los paisajes que presenta y los ecosistemas que contiene se expresarán en cartas geográficas y se rige por la Ley 99 de 1993.

Artículo 11. Unidades político-administrativas. Son unidades políticoadministrativas el Estado, los departamentos y los municipios, representan los tres niveles de la administración pública.

Parágrafo. Las restantes unidades, provincias, distritos, áreas metropolitanas y otras, tienen el carácter de unidades administrativas de coordinación.

Las unidades político-administrativas son antrópicas, las crea y decreta el hombre, las suprime y las modifica y "gozan de autonomía para la gestión de sus intereses" (CN. Art.287).

La ley de ordenamiento políticoadministrativo definirá las condiciones de creación de las político-administrativas, sus respectivas funciones, competencias $\mathrm{y}$ atribuciones y la manera de resolver los conflictos de competencias que surjan entre ellas. 
Las unidades político-administrativas, por razones que lo justifiquen, podrán unirse $\mathrm{y}$ formar asociaciones con objetivos y propósitos comunes.

1. Departamentos. Los departamentos son unidades político-administrativas dotadas de territorio, en que se divide el país, destinadas a su mejor administración. Sus funcionarios ejercerán funciones de intermediación entre los gobiernos locales y el gobierno central, de planificación para la formulación de planes de ordenamiento territorial y de desarrollo departamental; de generación de procesos de producción en empresas que ocupen a la población; de proyección y conducción de obras públicas; de orientación, coordinación y complementación de acciones municipales; de preservación del medio y del ambiente.

Los gobernadores de los departamentos tendrán funciones de dirección, planificación y coordinación de las actividades de los municipios que formaran el departamento,

Los gobernadores formarán el Consejo Nacional de Gobernadores que presidirá el Presidente de la República. El Consejo sesionará ordinariamente una vez cada dos meses y extraordinariamente cuando lo convoque el Presidente o lo solicite la mitad de los gobernadores.

2. Municipios. "El municipio es la entidad fundamental de la división político-administrativa del Estado" (CN Art.311).
Existirá municipio allí donde la gente se organice en un territorio, designe autoridades $\mathrm{y}$, tenga capacidad de autosostenerse. En esas condiciones, la ley lo reconocerá.

Los municipios tienen capacidad de "determinar su estructura administrativa municipal y las funciones de sus dependencias" (CN. Art.313, numeral 6). $\mathrm{Su}$ funcionamiento se dispondrá de acuerdo con sus propias circunstancias de lugar, población y capacidades, de las cuales dependerá su estructura administrativa y las funciones de sus dependencias.

Los municipios, que significan cercanía del gobierno a los ciudadanos, tendrán a su cargo el manejo de todo cuanto sea próximo y esencial al hombre: organización de la comunidad, cultura, vivienda, educación, salud, deportes, servicios públicos, policía, medio ambiente, conservación de los recursos naturales, ordenamiento territorial, fomento agrario, control de usos de la tierra y planeación del desarrollo local. Los municipios se dividirán en veredas y corregimientos.

Las veredas se organizarán como centros de vida y trabajo debidamente dotadas de los servicios que demande la óptima calidad de vida de la población veredal. En cada vereda se establecerá una Junta de Acción Comunal.

Las veredas se asociarán en Corregimientos. Estos dispondrán, cuando menos, de puesto de salud y puesto de policía. 
3. Territorios indígenas $y$ afrocolombianos. Los territorios indígenas se organizarán como municipios indianos teniendo en cuenta lo que les es específico, su etnia, su cultura su organizaciones tradicionales de sus habitantes. Los grupos afrocolombianos con las respectivas variaciones, se organizarán como municipios afrocolombianos en las tierras asignadas que les han sido asignadas comunitariamente.

4. Provincias. Las provincias son unidades territoriales conformadas por la asociación de municipios de un mismo departamento; estarán destinadas a profundizar la identidad de la población, a coordinar actividades de las unidades asociadas y a impulsar proyectos de interés subrregional.

5. Distritos. Los distritos son unidades administrativas de régimen especial que se conformarán y decretarán para el manejo de territorios que, por su naturaleza, requieren atención especializada.

6. Áreas metropolitanas. Area metropolitana es el conjunto formado por una metrópolis y las ciudades y poblaciones que la acompañan en proximidad. Les corresponderá formular y adoptar su respectivo plan de ordenamiento territorial y definir objetivos, criterios y normas, en igualdad de condiciones, que deben acoger y aprobar los municipios involucrados en el área.

Artículo 12. Ordenamiento étnico-cultural. El país contará con un plan nacional étnico-cultural que se reconocerá en la ley nacional de asentamientos humanos, base del ordenamiento urbanístico del territorio.

Artículo 13. Ordenamiento urbanístico. El ordenamiento urbanístico comprenderá la clasificación de centro poblados y se guiará por la Ley 388 de 1997.

Artículo 14. Ordenamiento rural. El ordenamiento rural y agrario del país se regirá por una ley específica que contemplará la continuidad espacial del campo, los elementos que lo conforman y su sustentabilidad; determinará la vocación productiva de los espacios continentales y sus regiones, las condiciones de la colonización de nuevos espacios y la ubicación y tratamiento de los asentamientos campesinos.

\section{Artículo 15. Ordenamiento infra-} estructural. El ordenamiento infraestructural contemplará la identificación y ubicación de obras y conjuntos de servicios públicos, producción eléctrica, instituciones de salud, educación y cultura, la vialidad en todas sus manifestaciones, las comunicaciones, la producción y conducción de energía y el tratamiento de aguas y basuras. El ordenamiento infraestructural se guiará por medio de una ley específica que contemplará las grandes obras de servicios para campesinos y ciudadanos.

Bogotá, junio de 2001 


\section{Ordenamiento Político Administrativo}

\section{Introducción}

"Para ordenar el país hay que ordenar el pensamiento" (Indígena aruhaco al profesor Edgar Rey Sinning).

1. Reforma política. El reordenamiento político-administrativo es la verdadera reforma política de la nación. Va más allá de organizar los partidos, las elecciones, los puntajes, la forma de hacer las listas de candidatos.

2. El planificador debe proponer lo óptimo, sin complejos. La realidad se encargará de poner las cosas en otro nivel. Pero el planificador no debe desilusionarse. Igual que el chino, no se hace ilusiones.

3. Aclarar conceptos. Diferenciar entidades territoriales de unidades políticoadministrativas. Entidad es todo aquello que tiene ser propio. Las entidades geográficas tienen ser propio. Las unidades político administrativas tienen ser pero no es propio, es prestado. Se las da el hombre que las crea. Son antrópicas.

4. Actualizar la nomenclatura. El atraso en viene de la Constitución de 1886. El artículo $5^{\circ}$ llamó entidades territoriales a los departamentos, municipios, intendencias y comisarías. La Constitución de 1991 (art. 286) llama entidades territoriales a departamentos, distritos, municipios, regiones, provincias $\mathrm{y}$ territorios indígenas resguardos). Siete entidades. Todas gozan de autonomía para la gestión de sus intereses.

5. Propuesta: Entidades territoriales son geográficas. Unidades políticoadministrativas son gobierno.

6. Objetivo para Colombia. Antecedentes: Venezuela, sembrar el petróleo, educación, industria. China; un taller. Israel: Hacer del desierto un jardín. Brasil: Potencia de Suramérica. 
7. Objetivo para Colombia. Hacer de Colombia una empresa comunitaria, un condominio, una nación de todos. Base, la economía solidaria. El estado colombiano será organizado como Estado Regional Unitario (Art. $1^{\circ}$ de la Constitución Nacional). Alternativo entre el estado federal y el estado centralista.

\section{Artículo primero de la Consti- tución. Leerlo. Ahí está todo}

\section{Organización Político-Administrativa}

Colombia se organizará con base en tres niveles de gobierno: el estado, los departamentos y los municipios. Las restantes unidades, provincias, distritos, áreas metropolitanas y otras, tienen el carácter de unidades apoyo y coordinación.

La ley de ordenamiento políticoadministrativo definirá las condiciones de creación de las político-administrativas, sus respectivas funciones, competencias $\mathrm{y}$ atribuciones y la manera de resolver los conflictos de competencias que surjan entre ellas.

\section{El Estado}

Definición. El estado es la forma en que se organiza una nación sobre un territorio determinado. La nación es la gente; el territorio es el país, la organización es política $\mathrm{y}$ administrativa. El estado es una forma de elevada convivencia. Por encima de todo un estado es una unidad de poder.
Objetivo. La razón de estado es la seguridad y el progreso de los asociados. Debe promover las libertades públicas, el ascenso histórico y cultural de la población. El estado unitario retiene las funciones centrales: dirigir la economía, las relaciones exteriores, la planificación y administración del conjunto, la justicia, la educación, la salud, las fuerzas armadas.

Las fuerzas armadas. Su misión la fijó en su testamento de Santa Marta, E1 Libertador Simón Bolívar: proteger las garantías sociales.

El estado es una empresa de seguridad social de la población y para la población. Es el Instituto de Seguros Sociales que requiere una reordenamiento. Dedicado a salud y a las jubilaciones.

Ramas de la administración. La administración del Estado se da en cuatro ramas: Legislativa, ejecutiva, judicial y de control es la rama ética (Bolívar).

Rama legislativa. Su sede es el Congreso. Dos cámaras no funcionan. Una cámara tampoco funciona. E1 problema es la gente que va a allí. La compondrá una sola cámara con 100 legisladores. Complementada con un cuerpo técnico asesor. Más visible, con menos gente, más económica, más fácil de controlar. El control debe hacerlo la ciudadanía. Se dispondrán condiciones que deben cumplir los candidatos a legisladores. Su objetivo es legislar y controlar al ejecutivo. Funcionará como una Junta Directiva de una empresa que 
representa los intereses de las regiones que conforman el país. El nuevo congreso es ilegal.

Rama ejecutiva. Es le gobierno, con el presidente, los ministros y planeación.

El presidente. Representa a la nación. Tiene credibilidad. Es un mandatario, hace el mandado. Y es un hombre de Estado, dirige el gobierno, inspira a la nación.

Preside: Consejo de ministros; 2 . Consejo de gobernadores. Consejo de embajadores, Estado Mayor.

Controles. Corte Constitucional. Fiscalía. Procuraduría. Contraloría. La Contraloría está en cada municipio. Un contralor organizará la comunidad para ejercer los controles que dispone la Constitución Nacional.

Financiación del estado. No transferencias que son un mecanismo de centralización y corrupción. Los aportes de la población por concepto de impuestos, tasas, contribuciones y regalías, forman un solo monto. $\mathrm{Se}$ distribuirá, $30 \%$ para funcionamiento del Estado. 70\% para funcionamiento de departamentos y municipios.

\section{El departamento}

Departamentos, son unidades políticoadministrativas dotadas de territorio, en que se divide el país, destinadas a su mejor administración. Sus unidades intermediarias entre los municipios y el gobierno nacional. Sus funciones: orientación, coordinación y complemen-tación de acciones municipales; planificación del desarrollo departamental y del ordenamiento territorial; proyección y conducción de obras públicas; preservación del medio y del ambiente. Se pueden unir y formar asociación. En el futuro, podrán coincidir sus territorios con los de las regiones geográficas.

Los departamentos son unidades transitorias, con modelo tomado del departamento francés, evolución de antiguas provincias de origen español, unidles en tránsito para transformarse en unidades regionales de administración planeación

Autonomía. La constitución autoriza a los departamentos a "determinar la estructura de la administración departamental, las funciones de sus dependencias, las escalas de remuneración. Otras discutibles, crear establecimientos públicos y empresas industriales o comerciales

Gobernadores de los departamentos tendrán funciones de dirección, planificación y coordinación de las actividades de los municipios que formaran el departamento. Formarán el Consejo Nacional de Gobernadores que presidirá el Presidente de la República. El Consejo sesionará ordinariamente una vez cada dos meses y extraordinariamente cuando lo convoque el Presidente o lo solicite la mitad de los gobernadores. Presidirán los Concejos Departamentales de Alcaldes. 
Equipo. Un órgano de planificación que depende directamente del gobernador. $\mathrm{La}$ Secretaría de gobierno se convierten en Secretaría de relaciones con la comunidad. Otras secretarías: Educación, Salud, Cultura (con acento en el comportamiento social y frente al medio), Obras Públicas, Medio Ambiente (sustentada en la bioética).

Asambleas, una concepción renovada las puede sustituir por Consejos Directivos. Con mínimo 12 miembros. Formados por alcaldes, por concejales, por ciudadanos elegidos en los municipios. Funciones: Controlar el ejecutivo. Estudiar y aprobar el plan de desarrollo, el presupuesto anual, evaluar lo cumplido el año anterior y direccionar lo que se debe cumplir en el año siguiente de acuerdo con el plan. Reciben viáticos y emolumentos por sesión, por lo menos tres al año.

\section{Municipios}

Municipios. "El municipio es la entidad fundamental de la división políticoadministrativa del Estado" (CN Art.311).

Definición. A partir del territorio: a partir de lo legal. A partir de la gente. Definición jus naturalista. Existirá municipio allí donde la gente se establezca un territorio, en se organice, designe autoridades, se dedique a resolver los problemas de la comunidad $\mathrm{y}$, tenga capacidad de autosostenerse. El municipio existe de manera natural. Definición positivista, el municipio es creación de la ley.
Los municipios tienen capacidad de "determinar su estructura administrativa municipal y las funciones de sus dependencias" (CN. Art.313, numeral 6). $\mathrm{Su}$ funcionamiento se dispondrá de acuerdo con sus propias circunstancias de lugar, población y capacidades, de las cuales dependerá su estructura administrativa y las funciones de sus dependencias.

Los municipios, significan cercanía del gobierno a los ciudadanos. Tendrán a su cargo el manejo de todo cuanto sea próximo y esencial al hombre: organización de la comunidad, cultura, vivienda, educación, salud, deportes, servicios públicos, policía, medio ambiente, conservación de los recursos naturales, ordenamiento territorial, fomento agrario, control de usos de la tierra y planeación del desarrollo local. La policía será municipal. Los municipios se dividirán en veredas y corregimientos.

Alcalde. Coordinador de la acción municipal desde las veredas. Preside el Consejo municipal de Acción Comunal (Hacer el país por acción comunal). Dirige la policía. El secretario de gobierno se transforma en un secretario de relaciones con la comunidad.

Veredas. El país se reorganizará desde las veredas y por acción comunal. ¿Qué es vereda? Se organizarán como centros de vida y trabajo debidamente dotadas de los servicios que demande la óptima calidad de vida de la población veredal. En cada vereda se establecerá una Junta de Acción Comunal articulada con las 
Unidades Municipales de Asesoría Técnica Agraria. UMATAS.

Las veredas se asociarán en Corregimientos. Estos dispondrán, cuando menos, de puesto de salud y puesto de policía.

1. Territorios indígenas y afrocolombianos. Los territorios indígenas se organizarán como municipios indianos teniendo en cuenta lo que les es específico, su etnia, su cultura su organizaciones tradicionales de sus habitantes. Los grupos afrocolombianos con las respectivas variaciones, se organizarán como municipios afrocolombianos en las tierras asignadas que les han sido asignadas comunitariamente.

2. Distritos. Los distritos son unidades administrativas de régimen especial que se conformarán y decretarán para el manejo de territorios que, por su naturaleza, requieren atención especializada.

3. Provincias. Las provincias son unidades territoriales conformadas por la asociación de municipios de un mismo departamento; estarán destinadas a profundizar la identidad de la población, a coordinar actividades de las unidades asociadas y a impulsar proyectos de interés subrregional.

4. Áreas metropolitanas. Area metropolitana es el conjunto formado por una metrópolis y las ciudades y poblaciones que la acompañan en proximidad. Les corresponderá formular y adoptar su respectivo plan de ordenamiento territorial y definir objetivos, criterios y normas, en igualdad de condiciones, que deben acoger y aprobar los municipios involucrados en el área.

Ley Orgánica es aquella que contiene, de manera integral, los principios que rigen un determinado tema, en este caso el del ordenamiento. La Ley Orgánica es una cúpula política, un modelo de arquitectura jurídica. Por naturaleza requiere aprobación por mayoría absoluta de votos. La Ley orgánica incluirá, por tanto, los tres ejes del el ordenamiento, territorial, étnico-cultural y político. Para su aplicación, la Ley Orgánica de Ordenamiento Territorial y Político, igual que la Constitución Nacional, para su debida aplicación, será desagregada en leyes particulares.

\section{Ley Orgánica de Ordena- miento Territorial y Político}

Colombia necesita una Ley Orgánica de Ordenamiento Territorial y Político. La Ley que cursa en el Senado de la República por estas fechas iniciales del siglo XXI, no es Orgánica, ni es integral. Es, solamente, una Ley de Ordenamiento Político-Administrativo y así debiera llamarse.

La ley en estudio tiene contribuciones importantes. En gracia de discusión, son oportunas las siguientes mejoras:

-Titularse simplemente Ley de Ordenamiento Político-Administrativo. 
-Eliminarse el título II que dispone la organización de la Comisión Nacional de Ordenamiento Territorial (CNOT). Dicho título debe tratarse como una ley o disposición independiente y aparte.

-Reconocer municipios no por el número de habitantes sino por la capacidad que tengan de sufragar sus gastos de funcionamiento.
-Dar a los indígenas un tratamiento de adultos y a sus unidades territoriales, Resguardos, darles la categoría de municipios indianos. Igual se hará con los territorios de las negritudes.

-Sustituir asambleas departamentales y concejos municipales por órganos más territorios de las negritudes -Sustituir asambleas departamentales y concejos municipales por órganos más funcionales $\mathrm{y}$ de menor costo. 